\title{
EFEITO E ATIVIDADE INSETICIDA DE Cinnamomum zeylanicum E Rosmarinus officinalis SOBRE Helicoverpa armigera Hübner,1908 (Lepidoptera:Noctuidae)
}

\author{
Cristhian Eliseo Durán Aguirre ${ }^{1}$ \\ Débora Ferreira Melo Fragoso² \\ Julielson de Oliveira Ataíde ${ }^{3}$ \\ Ana Clara Thezolin Acevedo ${ }^{4}$ \\ Patrícia Fontes Pinheiro 5 \\ Adilson Vidal Costa ${ }^{6}$ \\ Sabrina Buqueroni ${ }^{7}$ \\ Dirceu Pratissoli ${ }^{8}$
}

Resumo: A lagarta-do-algodoeiro, Helicoverpa armigera Hübner, 1908 (Lepidoptera: Noctuidae) é uma praga agrícola de grande importância econômica no mundo. O principal método de manejo desse inseto está baseado no uso de pesticidas sintéticos que acarretam efeitos negativos para a saúde humana, o meio ambiente e organismos no-alvos. Os óleos essenciais são metabolitos secundários derivados de plantas que tem ação inseticida em insetos pragas. Além disso, tem pouca persistência no ambiente, são degradáveis e não tem efeitos sobre inimigos naturais. O objetivo de este trabalho foi testar a ação inseticida dos óleos de canela, Cinnamomum zeylanicum e alecrim, Rosmarinus officinalis sobre lagartas de primeiro instar. Foram aplicados os referidos óleos a $5 \%\left(m^{-1}\right)$ diante pulverização e avaliou-se a atividade inseticida até 72 horas após tratadas. Os óleos essenciais não apresentaram atividade inseticida, mas, porém, poderiam ter efeitos subletais na biologia das insetos pragas.

Palavras-chaves: Plantas inseticidas; Controle biológico; Óleos essenciais; $H$. armigera.

\footnotetext{
1 Pós-graduação em Produção Vegetal/UFES, Brasil. E-mail: cduran-21@hotmail.com.

2 Pós-graduação em Produção Vegetal/UFES, Brasil. E-mail: debmelo@gmail.com.

3 Pós-graduação em Produção Vegetal/UFES, Brasil. E-mail: julielsonoliveira@hotmail.com.

${ }^{4}$ Pós-graduação em Produção Vegetal/UFES, Brasil. E-mail: clarathezolin@hotmail.com.

${ }^{5}$ Departamento da Química e Física/UFES, Brasil. E-mail: patriciafontespinheiro@yahoo.com.br.

${ }^{6}$ Departamento da Química e Física/UFES, Brasil. E-mail: avcosta@hotmail.com.

7 Graduação em Agronomia/UFES, Brasil. E-mail: sabrinabuqueroni21@gmail.com.

8 Diretor Pós-graduação em Produção Vegetal/UFES, Brasil. E-mail: dirceu.pratissoli@gmail.com.
} 